\title{
A ANÁlise DA MORTALIDAdE POR CAUSA BÁSICA E POR CAUSAS MÚLTIPLAS *
}

Ruy LAURENTI *

RSPU-B/236

LaURenti, R. - A análise da mortalidade por causa básica e por causas múltiplas. Rev. Saúde públ., S. Paulo, 8:421-35, 1974.

RESUMO: Foram comentados alguns aspectos das estatisticas de mortalidade por causas básicas e por causas múltiplas. Utilizando uma amostra de óbitos ocorridos em hospitais e obtendo informaçōes adicionais através dos prontuários médicos, foram refeitos os atestados comparando-os com os originais. Foi verificado que a causa básica está declarada incorretamente em $37,7 \%$ dos casos e que existem discordancias que se compensam. o numero médio de diagnósticos por atestados de óbito foi de 1,9, elevando-se para 2,9 quando se dispōem de informações adicionais. $O$ número médio de diagnósticos adicionais que acompanhou a causa básica aumentou quanto mais longa foi a evolução da doença básica. A codificação de causas múltiplas tem como vantagens o reconhecimento de freqüências de doencas que raramente são consideradas básicas e as estatisticas de mortalidade por causas múltiplas não são afetadas pelas mudanças das regras de seleção da causa de morte.

UNITERMos: Estatistica vital*; Mortalidade (causas básicas) *; Mortalidade (causas múltiplas) *; Atestados de óbito.

\section{N T R O D U C $\bar{A} O$}

As estatísticas de mortalidade constituem instrumento fundamental em saúde pública. Em epidemiologia representam uma das principais fontes de informações para numerosos tipos de estudos.

Os óbitos podem ser analisados quanto ao número e em relação a algumas variáveis, dentre outras, sexo, idade, local, tempo, etc., constituindo, entretanto, sua causa o aspecto mais importante.

Foi adotado sempre o sistema de se atribuir uma só causa a um óbito para efeito de tabulação de mortalidade. Essa causa, porém, não tinha uma definição uniforme em todos os países, assim como. variava de país para país o modelo de atestado de óbito no qual eram declaradas aquelas causas.

A "Conferência Internacional da Revisão da Classificação", ao aprovar em 1948 , a Sexta Revisão da Classificação Estatística Internacional de Doenças e Causas de obito, adotou um modelo de atestado de óbito (usado até hoje) e definiu qual a causa a ser tabulada nas estatísticas de mortalidade, que foi chamada a causa

* Parte da tese de livre-docência apresentada à Disciplina de Estatística Vital do Departamento de Epidemiologia da Faculdade de Saúde Pública da Universidade de São Paulo. Realizado com o auxílio financeiro da FAPESP (Proc. n.o 71/607)

* Da Disciplina de Estatística Vital do Departamento de Epidemiologia da Faculdade de Saúde Pública - USP - Av. Dr. Arnaldo, 715 - São Paulo, SP - Brasil 
LAURENTI, R. - A análise da mortalidade por causa básica e por causas múltiplas. Rev. Saúde públ., S. Paulo, 8:421-35, 1974.

básica ${ }^{16}$. Considerou-se que, do ponto de vista de prevenção de mortes, seria importante cortar a cadeia de eventos ou instituir a cura em algum ponto e que o objetivo mais eficaz da saúde pública é prevenir a causa precipitante, para que ela não atue. "Para estes propósitos a estatística mais simples é aquela relativa à causa básica da morte, a qual pode ser definida como (a) a doença ou lesão que iniciou a sucessão de eventos mórbidos que levou diretamente à morte, ou (b) as circunstâncias dos acidente ou violência que produziu a lesão fatal" ${ }^{16}$.

Vários estudos têm demonstrado que, embora seja adotado um modelo uniforme de atestado de óbito e uma definição precisa da causa básica, as estatísticas de mcrtalidade não são ainda inteiramente corretas. Isso se deve ao fato de, muitas vezes, não ser declarada a verdadeira causa básica ou então, mesmo sendo declarada, não o é de forma apropriada no atestado.

Dentre os vários estudos publicados, referentes à qualidade das informações contidas nos atestados de óbito, podem ser citados entre outros, JAMES et al. ${ }^{12}$ (1955), Moriyama ${ }^{18}$ (1960), BeAdenkopf et al. ${ }^{1}$ (1963), Moriyama et al. ${ }^{19,}{ }^{20}$ (1958 e 1966), Jablon et al. ${ }^{11}$ (1966), Milanesi \& Laurenti ${ }^{17}$ (1964), Puffer \& SerRANo ${ }^{23}$ (1973). O relatório sobre os problemas da certificação médica das causas de morte feito em 1958 pelo "Committee on Medical Certification of Causes of Death" 3, dos Estados Unidos, expôs importantes aspectos do problema e, citando extensa bibliografia, fez referências à falta de exatidão dos atestados, acentuando, porém, que seria possivel obter significante melhoria desde que os médicos tivessem um perfeito conhecimento do que é pedido na declaração das causas de morte.

Tendo-se em vista os erros que podem existir nas estatísticas de mortalidade que levam em conta somente uma causa e, principalmente, o fato de que nem sempre uma morte depende de uma só causa, há vários anos vem sendo sentida a neces- sidade de se obter estatísticas de mortalidade por causas múltiplas.

A causa básica dá origem a uma sucessão de afecções que são chamadas conseqüenciais, a última das quais chamada causa terminal ou direta. Outras causas que não entram na cadeia iniciada pela básica, e que no atestado devem ser declaradas na parte II são as chamadas causas contribuintes. As conseqüenciais e as contribuintes constituem o que se chama de causas associadas.

As estatísticas de mortalidade por causas múltiplas são aquelas obtidas pela classificação de todas as causas - básica e associadas - existentes nos atestados e apresentadas segundo essas características.

Vários autores têm destacado a importância das causas múltiplas em mortalidade e, dentre esses, podemos citar Dublin \& VAN BUREN ${ }^{8}$ (1924); JANSEN ${ }^{13}$ (1940); De Porte 4 (1941); Weiner et al. ${ }^{25}$ (1955); JAMES et al. ${ }^{12}$ (1955); Treolar $^{24}$ (1956); Moriyama et al. ${ }^{19}$ (1966); Erhardt ${ }^{\theta}$ (1958); Ollson el al. ${ }^{21}$ (1961); DORN \& MorIYAMA ${ }^{\top}$ (1964) ; Dorn ${ }^{5,6}$ (1964, 1966) ; KrueGER $^{14}$ (1966); GURALNICK ${ }^{10}$ (1966); Cohen \& Steinitz ${ }^{2}$ (1969) e Puffer ${ }^{22}$ (1970). Mais recentemente a importância da análise da mortalidade por causas múltiplas ficou sobejamente demonstrada na "Investigação de Mortalidade na Infância" (Puffer \& Serrano ${ }^{23}, 1973$ ).

Alguns aspectos têm sido invocados quando se salienta a necessidade de se analisar as causas múltiplas; alguns destes referem-se às críticas da mortalidade por causa básica e outros dizem respeito à importância, por si mesma, da análise das causas múltiplas, pela riqueza de informações que oferecem. A seguir serão expostos alguns destes aspectos.

O desconhecimento por grande parte dos médicos sobre a maneira correta de preencher o atestado, faz com que eles assinalem, muitas vezes, a causa básica de maneira incorreta, de tal forma que, mesmo aplicando as regras de seleção, ela não 
L IURENTI, R. - A análise da mortalidade por causa básica e por causas múltiplas. Rev. Saúde públ., S. Paulo, 8:421-35, 1974.

será codificada. A codificação de todas as causas mencionadas no atestado fará com que ela apareça sempre, não se perdendo, desta maneira, nenhuma informação.

As regras de seleção conferem a algumas doenças uma "menor prioridade", fazendo com que elas, mesmo informadas corretamente como básicas, sejam descartadas em favor de outras mencionadas. É o que ocorre, por exemplo, com a doença hipertensiva que freqüentemente é causa básica de afecções vasculares do sistema nervoso central e afecções cardíacas, e é informada, desta maneira, nos atestados. As regras de seleção dão, entretanto, prioridade àquelas afecções que são codificadas como básicas desaparecendo a hipertensão. A codificação de causas múltiplas traria o benefício de evidenciá-la sempre que mencionada.

Além das regras de selecão da causa básica deformarem a magnitude de algumas loenças, elas podem afetar artificialmente a tendência de outras. Isto ocorre quando há mudança das regras, o que se pode verificar com as sucessivas revisões da Classificação Internacional de Doenças. Segundo DoRv ${ }^{5}$ (1964) as mudanças acentuadas na tendência da mortalidade por uma doença podem ser devidas a mudanças das regras de seleção e não à mudança de comportamento da doença propriamente dita. Tal fato não existiria se todas as causas fossem codificadas.

Além destes aspectos é importante também ressaltar outros: para alguns óbitos, devido a certas doenças infecciosas agudas e certos tipos de acidentes, podemos aceitar uma só causa, porém, para grande número de mortes o que ocorre é que o óbito sobrevem devido a um complexo de causas.

DORN ${ }^{6}$ (1966), discutindo as causas múltiplas expõe a importância de se apresentar tabulações que contenham, além da causa básica, o total de vezes que um diagnóstico é mencionado. Isto permitiria: a) representar de maneira completa a frequiência total com que cada diagnóstico aparece; b) dar uma base mais racional para se conhecer a importância relativa de várias doenças como causa de morte; c) aumentar a utilidade das estatísticas de mortalidade para estudos epidemiológicos; d) melhorar a confiabilidade nas comparaçōes internacionais sobre causas de morte; e) fornecer elementos para julgar os efeitos das regras na seleção da causa básica; f) fornecer uma medida sobre os efeitos das mudanças das regras de seleção da causa básica na tendência dos coeficientes de mortalidade por causas específicas.

$O$ estudo das causas múltiplas torna possivel outro tipo importante de análise que é a associação de causas que podem ser vistas de duas maneiras. Lma delas é a que evidencia para cada causa básica quais as conseqüências ou complicações mais freqüentes; pensando em termos de prevenção da morte, não somente a nível primário, isso representaria uma grande contribuição. O outro tipo de associação que poderia ser evidenciado é aquele referente a duas causas específicas, não se considerando as consequiencias, mas sim a básica e a contributória. Tal fato vem a ter grande interesse em estudos epidemiológicos, principalmente, para doenças crônicas, como por exemplo, verificar as associações da diabete com as doenças arteriais, hipertensão, cardiopatias, nefropatias e outras. Mesmo para as doenças agudas ou infecciosas, este tipo de análise é importante. Assim, os resultados da "Investigação Interamericana de Mortalidade na Infância" ${ }^{23}$, mostraram elevado índice de mortalidade por doenças infecciosas (causa básica) associada com a desnutrição (causa contributória). A prevenção da mortalidade por doenças infecciosas em crianças não deve visar somente a esse grupo de causas, mas sim a ação deve dirigir-se ao binômio infecçãodesnutrição.

Em novembro de 1970, a Repartição Sanitária Panamericana reuniu no "Centro 
LAURENTI, R. - A análise da mortalidade por causa básica e por causas múltiplas. Rev. Saúde públ., S. Paulo, 8:421-35, 1974.

Latino Americano de la Classificación de Enfermedades", em Caracas, um grupo de estatísticos de saúde de alguns países latino-americanos, com a finalidade de discutir aspectos referentes às propostas à Nova Revisão da Classificação Internacional de Doenças; este grupo ressaltou a importância do estudo das causas múltiplas em estatísticas de mortalidade chamando a atenção para alguns resultados $\mathrm{da}$ "Investigação Interamericana de Mortalidade na Infância" que havia adotado, como metodologia, este tipo de análise.

O grupo de estatísticos de saúde propôs um estudo, "Investigação de Causas Múltiplas de Morte" que teria como finalidade analisar as causas básicas e associadas de óbitos tal qual são declaradas nos atestados de óbitos e essas mesmas causas após a obtenção de informaçōes adicionais. Um importante aspecto do estudo seria a comparação dos resultados, utilizando-se toda informação obtida com aquelas já existentes nos atestados para decidir como poderiam efetuar, ulteriormente, análises de causas múltiplas, utilizando somente os atestados, ou, se fosse necessária sempre a complementação das informações (Laurenti \& Silveira ${ }^{15}$, 1972). Os objetivos propostos para essa "Investigação" foram: 1) verificar a metodologia adequada para o estudo das causas múltiplas, em algumas áreas da América Latina; 2) verificar a qualidade das informações disponíveis e a factibilidade de estudos futuros; 3) desenvolver núcleos de interesse para o estudo de causas múltiplas; 4) verificar as associações de doenças mais freqüentes nos diferentes grupos de idade e sexo; 5) estudar a freqüuencia das doenças nos falecidos; 6) comparar os resultados obtidos no estudo de causas múltiplas baseados nos atestados com os obtidos com os dados registrados nos hospitais.

Para a realização da investigação, foram escolhidas várias cidades latino-americanas, incluindo São Paulo, onde a execução da pesquisa coube à Disciplina de
Estatística Vital do Departamento de Epidemiologia da Faculdade de Saúde Pública. Nesta apresentação serão relatadas apenas parte limitada dos resultados, com o objetivo de, quanto à causa básica, mostrar os erros existentes quanto à sua declaração, nos atestados originais, quando se comparam estes com os elaborados após informações adicionais que a investigação permitiu.

No que diz respeito às causas múltiplas, o que se pretende é mostrar a riqueza de informaçōes quando as mesmas são tabuladas, através do número de diagnósticos por atestado e a tabulação das causas múltiplas, relacionando-se para cada causa básica o número total de vezes que foi mencionada. Para esses aspectos os resultados serão comparados levando-se em conta os atestados originais e aqueles preenchidos após obtenção de informações adicionais.

A análise da associação de causas não será mostrada nesta apresentação.

$$
\text { M E T O D O O G A }
$$

Os óbitos estudados foram aqueles ocorridos em hospitais ou pronto-socorros e registrados no distrito de $\mathrm{S}$. Paulo, no período de $1 .^{\circ}$ de março 1971 a 29 de fevereiro 1972. O número de óbitos, neste período, foi estimado em 51.000 , sendo que, aproximadamente, $70 \%$ ocorriam em hospitais ou pronto-socorros. Como se pretendia estudar 1.800 óbitos adotou-se uma amostragem probabilística sistemática.

Os atestados sorteados eram investigados procurando-se obter o máximo de informações que estavam registradas nos prontuários médicos. Era preenchido, para cada caso, um questionário onde na primeira parte constavam: a identificação do falecido, o nome do hospital ou pronto-socorro, data da morte, todas as informações médicas existentes obtidas do prontuário, além do $(\mathrm{s})$ diagnóstico $(\mathrm{s})$. Todos os exames complementares eram copiados e, quando existia, também o laudo de autópsia. 
LAURENTI, R. - - A análise da mortalidade por causa básica e por causas múltiplas. Rev. Saúde públ., S. Paulo, 8:421-35, 1974.

Após a coleta de informações passava-se a preencher a segunda parte do questionário que contava de dois itens: atestado médico da causa de morte (cópia exata) e opinião do investigador (baseada no resumo da história clínica).

O primeiro, atestado médico da causa de morte (cópia exata), consistia no modelo internacional do atestado de óbito. com suas partes I e II, onde se transcreviam todos os diagnósticos como estavam nos atestados originais da amostra selecionada.

O segundo constava de duas partes: I (seqüencia principal) com as linhas "a", "b" e "c", como no modelo internacional do atestado de óbito, e além destas, existiam três outras abaixo que serviam para escrever outras causas que entravam na sequiência principal, adicionalmente àquelas escritas nas linhas "a", "b" e "c". A parte II (causas contributórias) constava de seis linhas, onde deviam ser informadas as causas que, existindo no momento da morte, não haviam entrado na seqüência formada a partir da causa básica (parte I).

Após ler todas as informações, o investigador preenchia o novo atestado de óbito (opinião do investigador), que era o segundo item da segunda parte do questionário. Era escrito na linha " $c$ " da parte I a causa que, em seu julgamento, foi considerada a básica e nas linhas " $b$ " $\mathrm{e}$ "a" as afecçôes conseqüenciais àquela. Quando havia mais de duas afecções consequienciais, estas eram anotadas nas linhas abaixo, porém ainda pertencente à parte I. Outras causas, existentes no momento da morte e que foram consideradas contribuintes, eram escritas na parte II.

Dos 1.895 atestados sorteados 63 foram excluídos pelos seguintes motivos: 58 pacientes não haviam falecido em hospitais, ainda que os atestados assim o declarassem; 2 casos não eram de óbitos, mas sim de perdas fetais; 1 caso foi sor- teado por engano (não era óbito hospitalar) e para 2 outros não havia, absolutamente, nenhuma informação (prontuários perdidos). Para alguns objetivos propostos nem sempre foi possivel utilizar os 1.832 casos restantes. Nos resultados, para cada objetivo, constará o número de casos estudados.

A codificação dos diagnósticos e a seleção da causa básica foram feitas segundo a Oitava Revisão da Classificação Internacional de Doenças.

Neste estudo não foram codificadas as causas mal definidas (categorias n. ${ }^{\text {s }} 780$ a 796 da Oitava Revisão) a não ser nos casos em que uma destas era a única informada em qualquer dos dois atestados, tanto no "original" como na "opinião do investigador".

Nos resultados quando se especifica "atestado original", isso dirá respeito àqueles preenchidos pelos médicos e que vão constituir a fonte das estatísticas oficiais de mortalidade. Os "atestados segundo opinião do investigador" ou simplesmente "opinião do investigador" dirão respeito aos novos atestados preenchidos, baseados em todas as informações obtidas.

\section{RESULTADOS E COMENTÁRIOS}

Comparação entre a causa básica selecionada no atestado original e aquela segundo a opinião do investigador

Quanto a esta comparação, verificou-se o seguinte para 1.828 casos:

1) Concordância dos quatro algarismos do código de doença: 934 casos $(51,1 \%)$

2) Concordância dos três primeiros algarismos do código da doença: 110 casos $(6,0 \%)$

3) Concordância apenas nos dois primeiros algarismos, porém, as duas causas básicas selecionadas pertencem a um mesmo agrupamento: 95 casos $(5,2 \%)$ 
LAURENTI, R. - A análise da mortalidade por causa básica e por causas múltiplas. Rev. Saúde públ., S. Paulo, 8:421-35, 1974.

4) Discordância que afeta a causa básica e seu agrupamento, sendo as duas causas básicas classificadas em diferentes grupos: 689 casos $(37,7 \%)$

Do ponto de vista de estatísticas de mortalidade, somente no último caso as doenças não são apresentadas num mesmo grupo de causas. Portanto, mesmo com as diferenças observadas, haverá concordância em $62,3 \%$ dos casos.

E importante ser realçado o fato de que em $37,7 \%$ dos casos não houve concordância quanto às causas básicas, as quais se classificaram em diferentes agrupamentos de doenças. Esse aspecto deve ser lembrado não só quando analisamos as características de mortalidade de uma área, mas também quando trabalhamos com essas informações para planejamento em saúde e em administração sanitária. Além disso, estudos epidemiológicos, baseados nessas estatísticas, poderão estar falhos.

Quando analisamos a concordância entre causa básica do atestado original $e$ aquela segundo a opinião do investigador. alguns aspectos precisam ser salientados. Assim é que, quando comparamos grupos de causas, verificamos que, para alguns, não existem grandes diferenças entre os valores observados, o que pode ser visto na Tabela 1, onde estão especificados alguns grupos de causas. Podemos observar que para vários deles, o número de vezes que uma causa aparece como básica no original é igual ao que aparece como básica na opinião do investigador e por vezes a diferença é muito pequena.

Se utilizarmos então os dados originais para determinados indicadores, não estaremos, para alguns grupos de causas, afastados do real. Certos indicadores usados em saúde pública, como por exemplo, mortalidade proporcional e coeficientes específicos por grupos de causas, apresentarão valores oficiais, globalmente considerados, não muito diferentes da realidade.

Deve porém ser destacado o fato de que, nem sempre, quando os valores são iguais ou próximos, isso significa que houve concordância de casos, ou seja, que estes são os mesmos. $O$ que se verificou é que existiram discordâncias, sendo estas, entretanto, compensadas. Esse fato, se não altera a mortalidade quanto às suas características numéricas, altera-a do ponto de vista qualitativo, pois a compensação de casos não respeita, obrigatoriamente, características importantes como sexo, idade, cor, profissão, etc. Assim sendo, epidemiologicamente, quando estamos analisando determinada doença e nos valemos de dados de mortalidade, ainda que numericamente não nos afastemos da realidade, podemos chegar a conclusões falsas quanto a certas características.

Na Tabela 1 é apresentado, para alguns. grupos de causas, o número de vezes que apareceram nos atestados originais e opinião do investigador. Apresenta, também, o número de vezes em que há concordância (mesmos casos), quando determinada doença é selecionada como causa básica no atestado original e pelo investigador.

Para algumas doenças, observaram-se interessantes aspectos tais como: as enterites e diarréias (A5) são mencionadas como causa básica $66,6 \%$ do que deveriam ser ( 156 vezes no original e 234 na opinião do investigador). Ocorreu, porém, que das 156 vezes que foi selecionada originalmente, somente em 126 ou $80,7 \%$ o investigador concordou com isso, e em 30 vezes ou 19,3\% ela não existia ou existia como doença, porém, não era a causa básica. Do ponto de vista de coeficiente de mortalidade ou mortalidade proporcional, essa causa estará, então, subestimada em $33,4 \%$. Se pensarmos em utilizar os dados de mortalidade para um estudo $\epsilon$ pidemiológico analítico, estaremos incorrendo, além disso, em outro erro correspondente a $19,3 \%$ das vezes.

As Doenças Hipertensivas (A82) foram, nos atestados originais, selecionadas como causa básica 18 vezes contra 32 na opinião do investigador; porém, das 18 em que foram originalmente selecionadas, apenas em $8(44,4 \%)$ houve concordân- 
LAURENTI, R. - A análise da mortalidade por causa básica e por causas múltiplas. Rev. Saûde públ., S. Paulo, 8:421-35, 1974.

T A B ELA 1

Número de vezes que algumas doenças (ou grupos) apareceram como causa básica nos atestados originais e na opinião do investigador e número de vezes que o investigador concordou com o original (mesmos casos)

\begin{tabular}{|c|c|c|c|c|c|c|}
\hline \multirow[b]{3}{*}{ Doenças * } & \multicolumn{2}{|c|}{ Causa básica } & \multicolumn{4}{|c|}{ Concordāncia entre (2) e (1) } \\
\hline & \multirow{2}{*}{$\begin{array}{l}\text { Origi- } \\
\text { nal } \\
\text { (1) }\end{array}$} & \multirow{2}{*}{$\begin{array}{l}\text { Opinião } \\
\text { do inves- } \\
\text { tigador } \\
\text { (2) }\end{array}$} & \multicolumn{2}{|c|}{ Sim } & \multicolumn{2}{|c|}{ Nāo } \\
\hline & & & N:P & $\%$ & N.D & $\%$ \\
\hline A5 - Enterites e Diarreias & 156 & 234 & 126 & 80,7 & 30 & 19.2 \\
\hline A6 - Tbc. Ap. Respiratório & 22 & 23 & 18 & 81,8 & 4 & 18,1 \\
\hline A47 - Tu. maligno do estômago & 27 & 33 & 26 & 96,3 & 1 & 3,7 \\
\hline $\begin{array}{c}\text { A65 - Avitaminose e outras de- } \\
\text { ficiências nutriciona1s }\end{array}$ & 71 & 23 & 10 & 14,0 & 61 & 85,9 \\
\hline $\begin{array}{l}\text { A72 - Meningites não meningo- } \\
\text { cócicas }\end{array}$ & 31 & 23 & 18 & 58.0 & 13 & 41,9 \\
\hline A82 - Doenças hipertensivas & 18 & 32 & 8 & 44,4 & 10 & 55,5 \\
\hline $\begin{array}{c}\text { A83 - Doenças isquêmicas do } \\
\text { coração }\end{array}$ & 137 & 133 & 103 & 75,1 & 34 & 24,8 \\
\hline $\begin{array}{c}\text { A85 - Doenças cérebro vascu- } \\
\text { lares }\end{array}$ & 131 & 136 & 113 & 86,2 & 18 & 13,7 \\
\hline A92 - Pneumonias & 214 & 92 & 75 & 35,0 & 139 & 65,0 \\
\hline Al02 - Cirrose hepática & 24 & 32 & 20 & 83,3 & 4 & 16,6 \\
\hline $\begin{array}{l}\text { A138 - Acidente de veículos a } \\
\text { motor }\end{array}$ & 56 & 71 & 56 & 100,0 & - & - \\
\hline A141 - Quedas acidentais & 8 & 22 & 7 & 87,5 & 1 & 12,5 \\
\hline
\end{tabular}

* Segundo a Lista A da 8:a Revisão da Classificação Internacional de Doenças.

cia com a opinião daquele, ou seja, eram os mesmos casos. Portanto, as 32 que apareceram na opiniāo do investigador não foram resultantes da soma das 18 originalmente relacionadas mais 14 , mas sim das 8 vezes em que "original" e "opinião do investigador" concordaram, mais 24 que apareceu só na opinião do investigador.

Os resultados obtidos mostraram que, para as neoplasias malignas, de maneira geral, para todos os tipos, não se verificaram alterações apreciáveis quanto ao número de vezes que apareceram como causa básica original e como causa básica na opinião do investigador. Além disso, na maioria das vezes que um determinado tipo de câncer foi informado no original, a opinião do investigador concordou com esses casos como tendo, realmente, a causa básica citada.

Tornar-se-ia exaustivo analisar causa por causa, sendo que a Tabela 1 expõe o fato claramente para algumas delas tomadas como modelo. E importante ressaltar, mais uma vez, os tipos de erros que são cometidos quando utilizamos estatísticas de mortalidade, segundo causas básicas, para determinados tipos de estudos. 
LAURENTI, R. - A análise da mortalidade por causa básica e por causas múltiplas. Rev. Saúde públ., S. Paulo, 8:421-35, 1974.

Número de diagnósticos (causas múltiplas) informados no atestado de óbito original e naquele segundo a opinião do investigador

Nos atestados originais foi informado um só diagnóstico em $31,7 \%$ dos casos e dois em $45,5 \%$. Nos $22,8 \%$ restantes foram informados três ou mais (Tabela 2). Em média, foram registrados 1,9 diagnósticos por atestado, evidenciando que, quando codificamos só causa básica estamos perdendo, praticamente, metade das informações.

Em 1958 a "National Vital Statistics Division" do "National Center for Health Statistics", codificou todas as causas informadas em uma amostra de atestados de óbitos dos Estados Unidos, tendo sido verificado que duas ou mais causas eram informadas em 58,0\% dos casos, sendo essa proporção $29,0 \%$ para óbitos de menores de 5 anos, a qual aumentava com a idade, atingindo, após 85 anos, $72,0 \%$. 0 número médio de diagnósticos, por atestado, foi 1,9 para todas as idades, sendo 1,4 para menores de 5 anos e 2,1 para aqueles de 85 anos e mais (DoRN ${ }^{6}, 1966$ ).

TABELA 2

Proporção de atestados "originais" e atestados "opiniāo do investigador" segundo o número de diagnósticos declarados

\begin{tabular}{ccc}
$\begin{array}{c}\text { N.o de } \\
\text { diagnós- } \\
\text { ticos }\end{array}$ & $\begin{array}{c}\text { Originais } \\
\%\end{array}$ & $\begin{array}{c}\text { Opiniăo do } \\
\text { investigador } \\
\%\end{array}$ \\
\hline & & \\
1 & 31,7 & 15,5 \\
2 & 45,5 & 29,4 \\
3 & 18,3 & 25,1 \\
4 & 3,7 & 15,4 \\
5 & 0,5 & 7,7 \\
6 & 0,0 & 3,8 \\
7 & 0,0 & 1,6 \\
8 & - & 0,8 \\
9 & 0,0 & 0,3 \\
\hline
\end{tabular}

Quando se obtiveram, através da pesquisa, todas as informações adicionais referentes aos casos estudados, e a partir delas era feito um novo atestado de óbito, verificou-se que somente $15,5 \%$ das vezes havia um só diagnóstico, em $29,4 \%$ havia dois. Em 55,1\% das vezes foram registrados três ou mais diagnósticos $(\mathrm{Ta}-$ bela 2) e o número médio de diagnóstico foi 2,9 .

A comparação entre o número de diagnósticos informados no atestado original e naquele segundo a opinião do investigador permite afirmar que, embora no atestado original se ganhe muito em informaçōes, ao se codificarem causas múltiplas, este número estará ainda aquém do total de informações que poderiam ser registradas. Os médicos, ao preencherem os atestados de óbito, deixam de informar estados patológicos que existiram e cujos diagnósticos foram feitos por eles mesmos, pois estavam registrados nos prontuários do hospital. Mais uma vez, surge o problema do preenchimento do atestado pelos médicos, pois, além do que já foi visto quanto à causa básica, eles omitem diagnósticos existentes. A omissão poderia ser, talvez, mais uma decorrência do modelo de atestado de óbito, do que uma falha do médico, pois esse modelo não o favorece, ou pelo menos não facilita a colocação de todas as informaçóes.

\section{Número de diagnósticos adicionais por causa básica}

A importância das causas múltiplas é lembrada, também, quando se leva em conta as doenças crônicas, degenerativas, que são de longa evolução e comumente estão associadas entre si, e com outras doenças, como é o caso das doenças arterioscleróticas, hipertensivas e do diabetes. Nesses casos não nos satisfaz pensar em uma só causa de morte. Para as doenças de curta duração, como a maioria das infecciosas, e para certos agravos à Saúde que levam à morte, como os acidentes 
LAURENTI, R. -- A análise da mortalidade por causa básica e por causas múltiplas. Rev. Saude públ., S. Paulo, 8:421-35, 1974.

ou violências, uma idéia que se tem é a de que são condições em que a causa básica é, na maioria das vezes, por si, suficiente para explicar a morte.

Nos atestados originais, para todas as causas básicas, houve, em média, 0,9 diagnóstico adicional, enquanto na opinião do investigador, ainda para todas as causas básicas, em média, houve 1,9 diagnósticos adicionais.

Quando se analisou causas especificas, verificou-se que o número médio de diagnósticos adicionais à básica variou conforme a doença considerada. Nestes resultados serão apresentadas algumas causas ou grupos de causas, entre essas, algumas de longa evolução e outras de evolução, geralmente, rápida. Segundo o atestado original e a opinião do investigador, o número médio de diagnósticos adicionais para cada uma dessas causas aqui apresentadas, está exposto na Tabela 3 .

$$
\text { TABEL } 3
$$

Número médio de diagnósticos adicionais por causa básica, segundo atestado original e opinião do investigador e para algumas causas ou grupos de causas

\begin{tabular}{|c|c|c|}
\hline Atestacio & $\begin{array}{l}\text { Origi- } \\
\text { nal }\end{array}$ & $\begin{array}{l}\text { Opinião } \\
\text { do inves- } \\
\text { tigador }\end{array}$ \\
\hline Infecciosas (A1-A44) & 0,9 & 2,0 \\
\hline $\begin{array}{l}\text { Neoplasias malignas } \\
\text { (A45-A60) }\end{array}$ & 1,0 & 1,8 \\
\hline Diabete (A64) & 1,9 & 2,6 \\
\hline $\begin{array}{l}\text { Doenças isquêmicas do } \\
\text { coração (A83) }\end{array}$ & 1,4 & 2,2 \\
\hline $\begin{array}{l}\text { Doenças cérebro-vascula- } \\
\text { res (A85) }\end{array}$ & 1,1 & 2,1 \\
\hline Perinatais (A.131-A135) & 0,7 & 1,5 \\
\hline Acidentes (A138-A145) & 0,8 & 1,1 \\
\hline
\end{tabular}

* Os números entre parêntesis referem-se ao número da doença na Lista $A$ da 8. $^{a}$ Revisāo de Classificação Internacional de Doenças.
Observa-se, na Tabela 3, que realmente os valores médios de diagnósticos adicionais para o diabetes $(1,9$ e 2,6$)$, doenças isquêmicas do coração $(1,4$ e 2,2$)$ e para as doenças cérebro vasculares $(1,1 \mathrm{e}$ 2,1) são maiores que aquelas observadas para o conjunto de todas as causas, quer nos atestados originais, quer na opinião do investigador (respectivamente, $0,9 \mathrm{e}$ 1,9).

As doenças infecciosas, quando causa básica no atestado original, apresentaram número médio de diagnósticos adicionais $(0,9)$ igual ao observado para todas as causas em conjunto, enquanto na opinião do investigador observou-se um número médio de diagnósticos adicionais mais elevado $(2,0)$.

Para as doenças infecciosas o que se torna mais notável é o fato de que, na opinião do investigador, o número médio de diagnósticos adicionais foi bastante alto em relação ao original, atingindo valores próximos aos observados para as doenças degenerativas. Tal fato poderia parecer estranho, tendo-se em vista que as infecciosas, pelo menos a maioria delas, tem evolução rápida, oferecendo pouca oportunidade de a elas se associarem outras. Além do mais, essas causas de morte seriam mais freqüentes em crianças, que por sua vez, não "acumulam" doenças degenerativas.

O que ocorreu, na opinião do investigador, é que em numerosos casos houve associaçōes com outras doenças quando a causa básica era infecciosa. Isso foi devido, principalmente, às associações com desnutrição, que na opinião do investigador existiu em $40,0 \%$ das vezes, ao passo que no original isso foi mencionado em apenas $15,0 \%$. Ainda, segundo a opinião do investigador, outras doenças infecciosas estavam associadas, aproximadamente, em $32,0 \%$ das vezes, contra somente $9,0 \%$ nos atestados originais. Outro fato que colaborou em parte, foi o de que, aproximadamente, $10,0 \%$ dessas mortes ocorreram em indivíduos de mais de 45 
LAURENTI. R. - A análise da mortalidade por causa básica e por causas múltiplas. Rev. Saíde públ., S. Paulo, 8:421-35, 1974.

anos, dando oportunidade ao aparecimento de outras causas, inclusive as degenerativas.

\section{Tabulação das causas múltiplas}

Ia Tabela 4 estão expostos os resultados relativos às causas de morte na amostra estudada. Nesta apresentação, escolheu-se somente algumas causas ou grupos de causas as quais aparecem segundo a Lista A da Classificação Internacional de Doenças, e para cada uma delas se vê o número de vezes que apareceu como básica e o total de vezes que foi mencionada, quer como básica, quer como associada. A Tabela 4 reune os resultados segundo os atestados originais (colunas 1 e 2 ) e a opinião do investigador (coluna 4 e 5 ).

A análise da Tabela 4 , por si só, mostra a importância de se classificar todas as doenças mencionadas nos atestados $e$ não somente aquela que foi considerada básica. Assim, nos atestados originais, isto é aqueles que vão constituir a fonte de dados para as estatísticas de mortalidade, quando se trabalha somente com causa básica, perdem-se muitas informações sobre doenças. Na presente amostra, a doença hipertensiva (A82) somente foi selecionada $17.8 \%$ das vezes em que foi mencionada; a desnutrição $(\mathrm{A} 65), 25,4 C^{\circ} \mathrm{C}$; o diabetes (A64), 48,9\%; e as anemias (A67). apenas $15.3 \%$. somente citando algumas causas.

É interessante comentar o que ocorre com a doença hipertensiva que no presente estudo apareceu como causa básica em apenas $17.8 \%$ das vezes que foi mencionada nos atestados originais e em $16,1 \%$ nos atestados feitos após obtenção de informaçōes adicionais (opiniāo do investigador). DORN \& MORIYAMA ${ }^{7}$ (1964) haviam assinalado em seu material de estudo que isso ocorria em $12,0 \%$. As doenças hipertensivas vão aparecer muito pouco nas estatísticas oficiais de mortalidade. mesmo sendo mencionada co- mo básica nos atestados. Este aspecto já havia sido salientado pela "Comissão de Peritos em Hipertensão e Doença Isquêmica do Coração", da Organização Mundial de Saúde ${ }^{26}$ (1962), que referiu "... Presentemente, a hipertensão arterial não é codificada como causa de morte quando é complicada por doença vascular, como a doença isquêmica do coração ou doença cérebro-vascular" Referindo-se a mesma questão, Dorx \& Moriyama : (1964) comentaram que. entre as doenças cardiovasculares, a hipertensão tinha pequena prioridade nas regras de seleção da causa básica de morte.

Para algumas causas, como as neoplasias malignas (A 45 a A60), existe. praticamente, uma igualdade entre o número de vezes que apareceram como básica e o total de vezes que foram mencionadas. Para as doenças infecciosas (Al a A44) e para os acidentes (Al38 a Al49) observaram-se também valores relativamente semelhantes.

A análise da Tabela 4 mostra. claramente. que o uso de estatísticas por causas básicas não mede corretamente, para a maioria das doenças. as freqüências das mesmas ra população de falecidos. Devemos ter em mente este fato quando utilizamos dados de mortalidade para estudos epidemiológicos e para programações em saúde. A utilização de todos os diagnósticos registrados nos atestados. e não só a de causa básica, fornece mais e melhores informações.

Dorx ${ }^{6}$ (1966) e DorN \& MoriyaMA ${ }^{7}$ (1964) apresentaram vários aspectos da tabulação de causas múltiplas e verificaram a mesma situação, quer evidenciada por outros autores, quer no presente trabalho, ou seja, a grande proporção de informaçoes perdidas quando se classifica somente causas básicas. e que variava de doença para doença.

Na Tabela 4 estão também as freqüências observadas para algumas doenças, 
LAURENTI, R. - A análise da mortalidade por causa básica e por causas mịltiplas. Rer. Saúde públ , S. Paulo, 8:421-35, 1974.

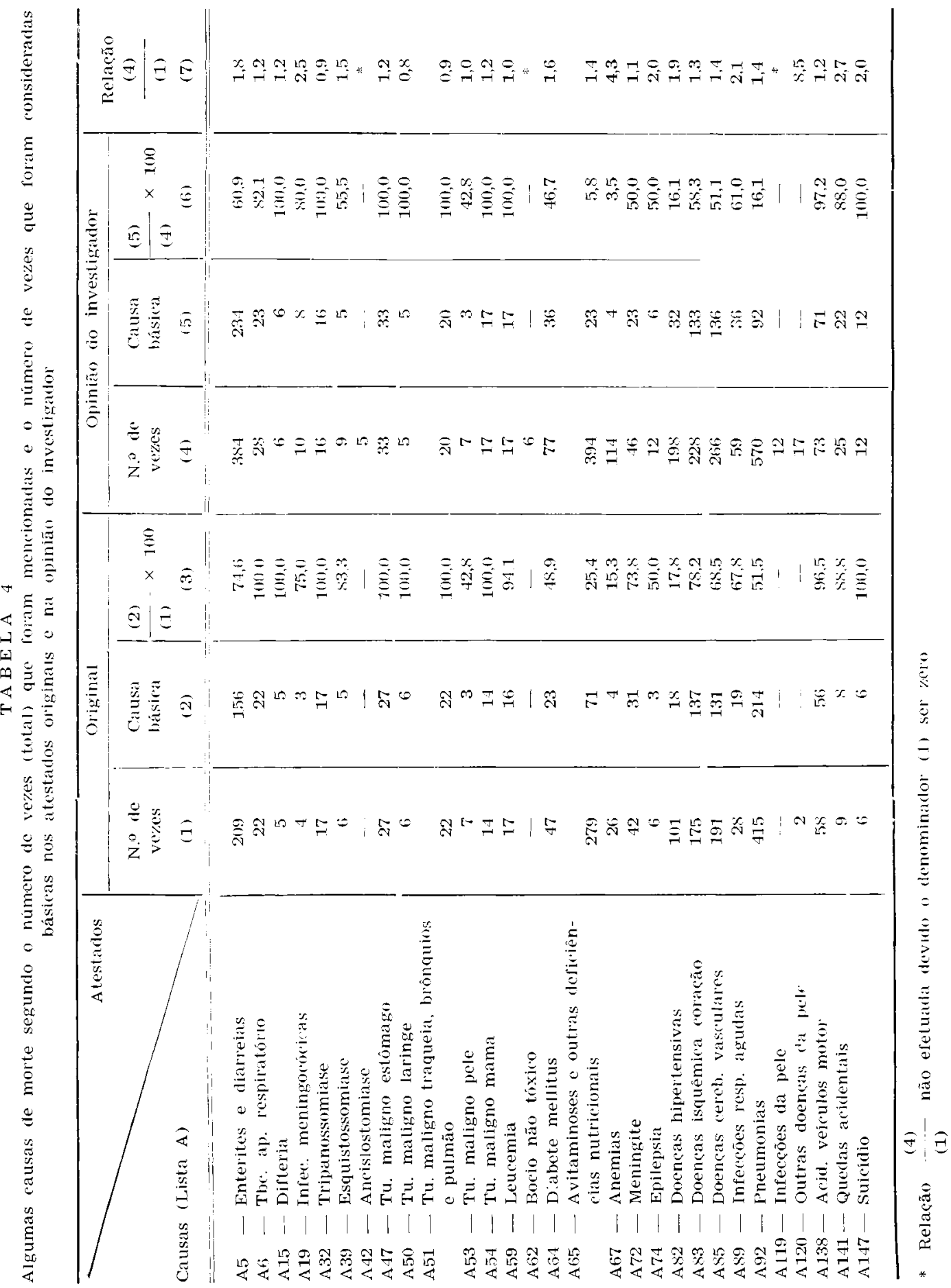


LAURENTI, R. - A análise da mortalidade por causa básica e por causas múltiplas. Rev. Saúde públ., S. Paulo, 8:421-35, 1974.

quer como básicas quer como o total de vezes em que foram mencionadas segundo opinião do investigador. Os resultados mostraram que, para a maioria das causas, elas deveriam, realmente, ser mencionadas maior número de vezes; a coluna (7) da Tabela evidencia a relação entre a opinião do investigador e o atestado original quanto ao número de vezes que uma doença foi mencionada. Como pode ser verificado esta relação é, muitas vezes, bastante elevada, chegando mesmo, para algumas doenças, ser observado o fato de não ter sido mencionada nenhuma vez nos atestados originais, quando na opinião do investigador deveria ter sido.

Assim, fica patente, pelos resultados, que utilizando informações adicionais obtidas dos prontuários médicos, houve um aumento de freqüência na maioria das doenças (comparação da opinião do investigador com os atestados originais).

Resultados semelhantes foram obtidos por Puffer ${ }^{22}$ (1970) que concluiu que as histórias clínicas e outras informações adicionais trazem muito mais conhecimento sobre a freqüência das doenças, do que utilizando somente os atestados de óbitos originais. A autora analisou o problema para várias causas específicas e, como exemplo, vamos citar o que ocorreu com o diabetes. Esta causa, nos atestados de óbitos originais, apareceu como causa básicd em $1,1 \%$ e $0,9 \%$ e, como causa básica ou associada (total de vezes), em $2,6 \%$ e $3,1 \%$, respectivamente para Bristol e S. Francisco, que foram as áreas estudadas. Valendo-se de informações adicionais obtidas de histórias clínicas e autópsias (o que corresponde à "opinião do investigador" do presente trabalho) havia menção de diabetes em $5,5 \%$ e $6,9 \%$ das mortes para aquelas duas cidades.

No material aqui estudado, praticamente para todas as causas, obtivemos os mesmos resultados da autora, pois quando uma doença aparece como causa básica sua freqüência é menor do que o número de vezes que é informada nos atestados originais. Por outro lado, se dispuzermos de informações adicionais, a freqüência aumenta ainda mais.

Tendo-se em vista estes resultados, uma dúvida que surge é se valeria a pena trabalhar com as causas múltiplas informadas nos alestados originais, sabendo-se que as frequiências das mesmas estão aquém do que deveria existir.

Nossa opinião é a de que o conhecimento das causas múltiplas e o seu uso deve ser estimulado em estatísticas de mortalidade, pois contribuirá ao melhor conhecimento dos problemas de saúde. Não achamos que se deva, de maneira alguma, abandonar as estatísticas por causa básicas, pois é importante em termos de prevenção primária. 0 que julgamos recomendável é que as apuraçōes sejam feitas, também, para todas as causas informadas nos atestados originais, o que melhoraria as informações, mesmo não se obtendo o número exato de ocorrência para várias causas.

Parece-nos mais simples obter-se dos médicos a declaração nos atestados de todos os diagnósticos existentes nos casos de morte, do que se tentar a melhora, tão somente, na declaração da causa básica. Os médicos entendem, aceitam e acham lógica a definição de causa básica e sua formulação, tendo-se em vista uma prevenção primária. Para determinadas doenças, porém, assim como para estados de pequena gravidade de algumas outras, não aceitam ou "não acham justo" que elas sejam selecionadas como básicas para aparecerem nas estatísticas de mortalidade. Entre outros, é o caso de doenças não muito graves e cujos portadores são submetidos a cirurgia, falecendo nesta por 
LAURENTI, R. - A análise da mortalidade por causa básica e por causas múltiplas. Rev. Saúde pübl,, S. Paulo, 8:421-35, 1974.

uma complicação; é também o caso de acidentes que, ocasionando lesões, por vezes leves, evoluem com uma complicação tipo septicemia, choque anestésico ou outra, vindo a terminar com a morte. Nestes casos, ou em outros semelhantes, há uma resistência dos médicos ao informar, corretamente, a causa primária no atestado, tal que pudesse ser selecionada como básica. Os médicos, quando inqueridos nesses casos, respondem que, ou não informam a causa básica preferindo a complicação ou, em caso positivo, colocam-na na parte II.

Nossa opinião é a de que deveria ser mostrada aos médicos a necessidade de declararem todas as doenças no atestado, visto serem essas informações importantes, sob vários aspectos, em Saúde Pública, principalmente em epidemiologia. Seriam tabuladas, assim, todas as causas que estivessem presentes no momento da morte, não importando se fosse básica, complicação desta, ou se uma causa contribuinte. Continuaria a existir o conceito de causa básica e estas seriam assim apuradas; mas naqueles casos em que os médicos não a julgassem assim ou não quisessem assim declará-las no atestado, o simples fato de colocá-las, em qualquer posição, faria com que essa informação não fosse perdida.

A solução, no nosso entender, é um programa educativo junto aos médicos e futuros médicos, para que passem a anotar no atestado de óbito todos os diagnósticos feitos em cada caso. Voltamos a insistir sobre a maneira pela qual mais $\mathrm{fa}-$ cilmente será alcançado o objetivo de melhorar as estatísticas de mortalidade, que será mais através da tabulação de causas múltiplas, do que o simples enfoque segundo a causa básica.
C O N C L U S O E S

1) Utilizando informaçōes adicionais (registros de histórias clínicas, exames subsidiários, laudos de autópsias) para refazer o atestado de óbito foi possivel identificar a causa básica, diferente da declarada correntemente nos atestados de óbitos originais em $37,7 \%$.

2) 0 estudo do comportamento de determinada causa de óbito como básica, dispondo-se de informações adicionais, evidencia menor proporção de divergências em decorrência de discordâncias que se compensam.

3) 0 número médio de diagnósticos por atestados de óbito, quando são disponíveis informaçóes adicionais, elevou-se de 1,9 para 2,9 .

4) O número de diagnósticos adicionais que acompanhou a causa básica aumentou, quanto mais longa era a evolução da doença reconhecida como tal.

5) A apuração de todos os diagnósticos informados nos atestados de óbito permitiu o reconhecimento da freqüência de doenças não selecionadas como causa básica, inclusive as que raramente são assim apuradas, achado de considerável utilidade para o estudo da história natural das entidades mórbidas.

6) As revisôes periódicas da Classificação Internacional de Doenças $e$ as modificações das regras de seleção da causa básica da morte, não terão influência sobre as estatísticas elaboradas quando são colhidas dos atestados de óbito todos diagnósticos informados. 
LAURENTI, R. - A análise da mortalidade por causa básica e por causas múltiplas. Rev. Saúde públ., S. Paulo, 8:421-35, 1974.

RSPU-B/236

LAURENTI, R. - [Analysis of mortality by underlying and multiple causes of death.] Rev. Saúde públ., S. Paulo, 8:421-35, 1974.

SUMMARY: Some aspects of mortality statistics based on underlying and multiple causes of death are analysed. A sample was drawn for study from deaths ocurred in hospitals using the official death certificates. With the help of additional information taken from medical records the death certificates were filled out again and compared with the original ones showing that the basic cause of death was incorrectly stated in $37.7 \%$ of the official death certificates and that there were some counterbalancing divergences. The average number of diagnosis per official death certificate was 1.9. With additional information it went up to 2.9. The longer the evolution of the basic illness, the greater the increase of the average number of additional diagnosis accompanying the basic cause. The multiple causes of death classification allowed acknowledgement of rare causes of death that very seldomly appeared as underlying causes of death. The mortality statistics by causes are not affected by the changes in the rules of death cause selection.

UNITERMS: Death, cause and multiple causes*; Vital statistics*; Death certificate*.

\section{REFERENCIAS BIBLIOGRAFICAS}

1. BEADENKOPF, W.G. et al. - An assesment of certain medical aspects of death certificate data for epidemiological study of artherioesclerotic heart diseases. J. chron. Dis., 16: 249-62, 1962.

2. COHEN, J. \& STEINITZ, R. - Underlying and contributory causes of death of adult males in two districts. J. Chron. Dis., 22:17-24, 1969.

3. COMMITEE ON MEDICAL CERTIFICATION OF CAUSES OF DEATH. Statistical Section - Problems in the medical certification of cause of death. Amer. J. publ. Hlth., 48: $71-80,1958$.

4. DE PORTE, J.V. - Mortality statistics and the physician. Amer. J. publ. Hlth., 31:105-6, 1941.

5. DORN, H.F. - Some considerations in the revision of the International Statistical Classification. Publ. Hlth. Rep., 79:175-9, 1964.

6. DORN, H.F. - Underlying and contributory causes of death. In: HAENSZEL, W. ed. - Epidemiological approaches to the study of cancer and other chronic diseases. Bethes- da, Md., National Cancer Institute, 1966. p. 421-30.

7. DORN, H.F. \& MORIYAMA, I.M. Use and significance of multiple cause tabulations for mortality statistics. Amer. J. publ. Hlth., 54: 400-6, 1964.

8. DUBLIN, L.I. \& VAN BUREN, G.H. - Contributory causes of death their importance and suggestions for their classification. Amer. $J$. publ. Hlth., 14:100-5, 1924.

9. ERHARDT, C.L. - What is "the cause of death"? J. Amer. Med. Ass., 168: $161-8,1958$.

10. GURALNICK, L. - some problems in the use of multiple causes of death. J. chron. Dis., 19:979-90, 1966.

11. JABLON, $\mathrm{S}$, et al, - On the significance of cause of death as recorded on death certificates in Hiroshima and Nagasaki, Japan. In: HAENSZEL, W. ed. Epidemiological approaches to the study of cancer and others chronic diseases, Bethesda, Md., National Cancer Institute, 1966. p. 445-65. 
LAURENTI, R. - A análise da mortalidade por causa básica e por causas múltiplas. Rev. Saúde públ., S. Paulo, 8:421-35, 1974.

12. JAMES, G. et al. - Accuracy of cause of death statements on death certificates. Publ. Hlth. Rep., 70:39-51, 1955.

13. JANSEN, T.A. - Importance of tabulating multiple causes of death. Amer. J. publ. Hlth., 30:871-9, 1940 .

14. KRUEGER, D.E. - New numerators for old denominators - Multiple causes of death. In: HAENSZEL, W. ed. - Epidemiological approaches to the study of cancer and other chronic diseases. Bethesda, Md., National Cancer Institute, 1966. p. 431-43.

15. LAURENTI, R. \& SILVEIRA, M.H. Causas múitiplas de morte. Rev. Saúde públ., S. Paulo, 6:97-102, 1972.

16. MANUAL of the international statistical classification of diseases, injuries, and causes of death, 6th revision. Geneva, World Health Organization, 1948.

17. MILANESI, M.L. \& LAURENTI, R. O estudo interamericano de mortalidade em S. Paulo. I - Estudo atual da certificação médica da causa de óbito no distrito da Capital. Rev. Ass. med. bras., 10:111-6, 1964.

18. MORIYAMA, I.M. - Factors in diagnosis and classification of death C.V.R. diseases. Publ. Hlth. Rep., $75: 189-95,1960$.

19. MORIYAMA, I.M. et al. - Evaluation of diagnostic information supporting medical certification of deaths from cardiovascular diseases. In: HAENS-
ZEL, W. ed. Epidemiological approaches to the study of cancer and other chronic diseases. Bethesda, Md., National Cancer Institute, 1966. p. 405-19.

20. MORIYAMA, I.M. et al. - Inquiry into diagnostic evidence supporting medical certiflcation of death. Amer. J. publ. Hlth., 48:1376-87, 1958.

21. OLSON, F.E. et al. - A study of multiple causes of death in California. J. chron. Dis., 15:157-70, 1961.

22. PUFFER, R.R. - Estudio de multiples causes de defuncion. Bol. Ofic. sanit. panamer., 69:93-114, 1970.

23. PUFFER, R.R. \& SERRANO, C.V. Patterns of mortality in chidhood. Washington, D.C., Pan American Health Organization, 1973. (Scientific Publication, 262).

24. TREOLAR, A.E. - The enigme of cause of death. J. Amer. Med. Ass., $162: 1376-9$, 1956.

25. WEINER, L. et al. - Use of multiple causes in the classification of deaths from cardiovascular-renal diseases. Amer. J. publ. Hlth., 45:492-501, 1955.

26. WORLD HEALTH ORGANIZATION, Expert Committee on Arterial Hipertension and Ischaemic Hearth $\mathrm{Di}$ sease, Geneva, 1961. Arterial hipertension and ischaemic heart disease: preventive aspects reports. Geneva, 1962. (Tech. Rep. Ser., 231).

Recebido para publicação em 17/9/1974 Aprovado para publicacão em 4/10/1974 